\title{
Lessons from beyond the Great Wall: what cross-cultural management researchers can learn from the Middle Kingdom
}

\author{
Kevin Lo and Snejina Michailova* \\ Department of Management and International Business, \\ University of Auckland Business School, \\ Private Bag 92019, 1142 Auckland, New Zealand \\ E-mail: kevin.lo@auckland.ac.nz \\ E-mail: s.michailova@auckland.ac.nz \\ *Corresponding author
}

\begin{abstract}
This paper revisits three studies conducted in the context of China to demonstrate how a single culture has eluded explanation by some of the most well-known cross-cultural studies as well as rendered valid, reliable scales from Western contexts inadequate in that culture. We suggest that cross-cultural researchers can utilise less-explored research contexts to further develop the sophistication of research by

a identifying emics

b aiming at cultural completeness

c contextualising and meaningfully incorporating indigenous thought and knowledge.

Looking beyond the three studies, we address the issue of intra-cultural variation, which can assist us to formulate truly cross-cultural approaches, both conceptually and methodologically, and to capture cross-cultural differences that might otherwise be lost to pseudo-etic or parochial approaches.
\end{abstract}

Keywords: cross-cultural management research; Chinese management studies; emics; cultural completeness; indigenous thought; intra-cultural variation.

Reference to this paper should be made as follows: Lo, K. and Michailova, S. (2010) 'Lessons from beyond the Great Wall: what cross-cultural management researchers can learn from the Middle Kingdom', European J. Cross-Cultural Competence and Management, Vol. 1, Nos. 2/3, pp.188-196.

Biographical notes: Kevin Lo is a Lecturer in the Department of Management and International Business at the University of Auckland Business School, New Zealand. He received his PhD from the University of Hawaii at Manoa in International Management focused on the Asia-Pacific region. His research interests include cross-cultural management, cross-cultural training, China, guanxi and networks, and organisational behaviour.

Snejina Michailova is a Professor of International Business in the Department of Management and International Business at the University of Auckland Business School, New Zealand. Originally from Bulgaria, she received her PhD from Copenhagen Business School, Denmark. Her research areas are in international management and knowledge management and she has published widely in these areas. She was an Editor Europe of Journal of World Business from 2001 to 2007, is currently an Associate Editor of Critical Perspectives on International Business and a member of the Editorial Boards of several international academic journals. 


\section{Introduction}

Management research has been described as a 'parochial dinosaur' because of deep entrenchment in a North American paradigm that represents various contextual, quantitative, and qualitative biases (Boyacilliger and Adler, 1991). Although the USA took an early lead in the 1960s with respect to management research, the reality in which we now live and work can no longer be confined to examination through apertures with a US filter. Clearly, not all management research is conducted in a US or North American context. However, the preponderance of research questions as well as their accompanying theories and methods still have roots in a distinctly Western, if not US-based, tradition. In spite of a keen interest in cross-cultural studies, there is still a dearth of writing on theories and methods in cross-cultural management research that prevents movement away from this North American bias (Easterby-Smith and Malina, 1999; Frese, 2005).

Nearly 20 years after Boyacigiller and Adler (1991) sounded their call to the Academy of Management, the state of the world is dramatically different, but cross-cultural research still suffers from biases and a general failure to capture the subtle nuances of differences and similarities, both across and within cultures. We see this shortcoming as highly problematic. As most of contemporary business takes place in an international context, it is urgent to refine our approaches to understanding details and nuances, which are difficult or impossible to spot at first glance. If cross-cultural management research cannot be at the forefront of identifying and exploring these nuances from sound cross-cultural theoretical perspectives, it will not be able to lead and inspire management practice.

We interpret the launch of the European Journal of Cross-Cultural Competence and Management as an important step towards tapping into the intellectual diversity as well as variety in articulation styles characteristic for academic and research spaces outside of North America. The timing cannot be more appropriate as the state of world affairs, while admittedly ever-changing, at present offers a unique situation in which the interplay of culture with economic, political, and social forces is unparalleled by any other period in modern history. Thus, the research questions cross-cultural management researchers ask and the theories and methods they utilise to derive their findings must necessarily take into account these situational forces that increase the complexities of culture.

In this paper, we turn our eyes to the Middle Kingdom and provide three examples of how cultural specificities have eluded prior explanation by research questions and methodological approaches. All three studies were conducted in the context of China, a context that has presented unique cross-cultural challenges and findings: the Chinese Culture Connection (1987) on Confucian dynamism, Cheung et al. (1996) on the Chinese Personality Assessment Inventory (CPAI), and Farh et al. (1997) on a Chinese version of an organisational citizenship behaviour (OCB) scale. These studies have developed cross-cultural dimensions and/or assessment scales specific to Chinese culture and have not only extended, but substantially enriched previous/original research findings.

Our inquiry reveals a powerful example of how a single culture has eluded explanation by some of the most well-known cross-cultural studies as well as rendered valid, reliable scales from Western contexts inadequate in that culture. Drawing lessons from these three studies, we suggest that cross-cultural researchers can utilise less-explored research contexts to further develop the sophistication of research by identifying emics and assuming differences rather than similarities, paying attention to 
and utilising cultural completeness, and contextualising and meaningfully incorporating indigenous thought and knowledge. Finally, and looking beyond the three studies, we address the issue of intra-cultural variation which can assist us to formulate truly cross-cultural approaches, both conceptually and methodologically, to capture cross-cultural differences that might otherwise be lost to pseudo-etic or parochial approaches.

\section{Where research has been extended and enriched: the case of China}

\subsection{The Chinese values survey}

Substantial work has been conducted on cultural values (e.g., Hofstede, 2001; Rokeach, 1973; Schwartz, 1992). Following in this tradition, the Chinese Culture Connection (1987) sought to codify cultural dimensions that were not rooted in a Western cultural context. The result of their investigation was the Chinese Values Survey (CVS), a 40-item questionnaire, which unlike other cultural value surveys centred around a Chinese Confucian ethos. University students in 22 countries were asked to indicate on a 9-point scale how important each of the 40 values was to them. China, not being included in the initial CVS, ranked highest on the Confucian work dynamism dimension among all 23 countries in a later data collection (Hofstede, 1994, 2001).

Of the four dimensions captured by the CVS, three converged with cross-cultural dimensions from Hofstede's (1980) work. $\mathrm{CVS}_{1}$-Integration converged negatively with Power Distance, $\mathrm{CVS}_{\mathrm{IV}}$-Moral Discipline converged negatively with Individualism, and $\mathrm{CVS}_{\mathrm{III}}$-Human Heartedness converged with Masculinity. The strong correlations between these three dimensions of the CVS and Hofstede respectively indicate that they are culture free. However, the remaining dimension, $\mathrm{CVS}_{\mathrm{II}}-$ Confucian Work Dynamism did not correlate to any of Hofstede's dimensions, thereby suggesting the existence of a culture-specific dimension that had been untapped by previous research. The eight Confucian dynamism values - persistence, ordering relationships by status, thrift, having a sense of shame, face protecting, reciprocation of favours, personal steadiness and stability - are deeply rooted in Chinese national culture (Fang, 2003).

Confucian dynamism has been characterised as 'strange' and 'difficult to comprehend' by Westerners (Fang, 2003; Hofstede, 2001; Newman and Nollen, 1996). Tsui et al. (2007), too, confirmed that this is the least utilised national cultural dimension in cross-national, cross-cultural organisational behaviour research. Herein, we have an example of how certain facets of a national culture, in this case China, had not received sufficient attention in prior work in spite of the existence of instruments designed to measure culture.

\subsection{The CPAI}

In cross-cultural research, there is recognition that borrowing instruments developed in one cultural context might bias results when translated and administered in another culture. In previous personality research, use of certain instruments, in this case the Minnesota Multiphasic Personality Inventory, suffered from the aforementioned difficulty of adapting an assessment inventory that had been created with one normative population to use with local, indigenous populations. This difficulty revealed an obvious deficiency 
that simultaneously highlighted a Western bias and exposed its inadequacy when taken out of the context of the original normative population (Butcher, 1985; Cheung, 1985). Remedies for problems such as this included considering cross-cultural differences in interpreting scores, establishing local norms to explain scores, and deleting items with poor discrimination power, but the more general problem endemic to each of these methods in attempting to generate cross-cultural equivalence was the omission of indigenous constructs (Cheung et al., 1996).

As a remedy to this problem, Cheung and colleagues used an emic/etic approach to develop an indigenous omnibus personality inventory to be used in Chinese culture: the CPAI. Besides taking a starting point in personality assessment methods used in Western countries and in constructs commonly used in English-language psychological tests, the Chinese inventory additionally considers the specificities of the Chinese culture. Personality scales with uniquely emic Chinese characteristics emerged from their research to uncover a Chinese personality type not captured in personality assessments that have proven reliability in Western cultural contexts. These included harmony, relationship orientation (ren qin), thrift, modernisation, defensiveness (Ah-Q mentality), and face (Cheung et al., 2001). Furthermore, when the CPAI was compared to the revised NEO-PI-R model popular in Western personality research, two factors were found to be unique: interpersonal relatedness was unique to the CPAI, but openness was not represented by the CPAI. As such, both uniquely Western and Chinese personality types were revealed by this comparison. However, short of the diligent efforts of Cheung and colleagues, this uniquely Chinese personality type might still remain a mystery.

\subsection{The Chinese version of an $O C B$ scale}

OCB is defined as individual behaviour that is discretionary, not directly or explicitly recognised by the formal reward system, and that in the aggregate promotes the effective functioning of the organisation' [Organ, (1988), p.4]. Organ (1988) identified five dimensions of OCB, and Podsakoff et al. (1990) later operationalised them. These dimensions were: civic virtue, altruism, conscientiousness, sportsmanship, and courtesy.

Farh et al. (1997) examined these dimensions of this OCB scale with its high reliability in a Western context acknowledging, however, that little was known about OCB in a global context. Going beyond previous research, they considered these OCB dimensions in juxtaposition to the unique cultural case of China and developed a Chinese OCB scale. Their Chinese model yielded five factors; three of them converged with factors in the Western OCB scale: civic virtue, altruism, and conscientiousness from the Western OCB scale related to identification with company, altruism towards colleagues, and conscientiousness from their Chinese OCB scale. However, as both scales yielded five factors, the remaining two items from each scale were determined to be emics of OCB in the respective cultures. Thus, sportsmanship and courtesy were emics of Western OCB. Conversely, interpersonal harmony and protecting company resources were emics of Chinese OCB.

Farh et al. (1997) cite Chinese cultural roots, particularly family orientation or what Schwartz (1990) calls familistic collectivism, as the difference in factors between the Chinese and Western OCB scales. As a result of familistic collectivism, in-group favouritism is stronger. While in-group/out-group distinctions have been explored previously in cross-cultural research, their manifestations as cross-cultural differences in 
OCB behaviour had been previously unexplored. Accordingly, the work of Farh et al. (1997) used the Chinese cultural context to extend previous research and create a Chinese OCB scale with high validity and reliability to parallel the Western OCB scale.

\section{What can we learn from the three studies? What are the implications for cross-cultural research?}

As cross-cultural researchers, part of what fuels our work is the acknowledgement that there is still much to learn about culture and about cross-cultural differences and similarities. We as cross-cultural researchers must continue to make these pioneering efforts to reveal the hidden dimensions of culture. Only through diligent efforts will our work be meaningful to a broader academic audience and to management practice. It is our responsibility to ensure accurate investigations of culture. The examples described in the previous section all provide evidence of how a single culture has revealed constructs beyond what previous research had identified. This research through both theoretical and methodological contributions extended the major dimensions of cross-cultural theory, personality typologies, and OCB. Three particular issues crystallise when looking across the three studies and with which, we argue, cross-cultural researchers should engage more in the future: identifying emics, aiming at cultural completeness, and incorporating meaningfully indigenous thought and knowledge. We briefly detail these issues below.

\subsection{Identify emics}

The assumption of similarities under the pseudo-etic approach has proven problematic because there are often emic manifestations of etic constructs. In fact, Triandis and Marin (1983) found the emic plus etic approach superior to the pseudo-etic approach. Each of the three studies that we reviewed demonstrates how there are culture specific variants of constructs. Additionally, all three studies revealed emics of Chinese culture that were missed by previous research because it had not accounted for culture specific differences. Thus, rather than a pseudo-etic approach, we suggest that cross-cultural researchers start by looking for emics and derive etics from lack of differences rather than deriving emics from lack of similarities. In other words, start with culture as a variable or known difference instead of extending theory or developing instruments specific to another cultural context ex post facto. This change equates to a fundamental shift in the approach of researchers to an assumption of differences from the outset, rather than similarities. With such an approach, however, researchers would be aware of the differences between cultures yet still be able to identify similarities when cultures do not differ. We believe this way of framing research will guard against emic properties being inadvertently missed thus forcing a re-examination of phenomena in a different cultural context.

\subsection{Aim for cultural completeness}

We also advocate aiming for cultural completeness in cross-cultural research. Culture completeness suggests that research examines emics of multiple cultures so that models, theories, and constructs are truly generalisable in a cross-cultural sense. If executed appropriately according to the above recommendation, the benefits are two-fold. First, this broad-sighted approach will maximise the likelihood of identifying emics because 
fundamentally researchers will be searching for differences. Second, where there are no differences, the cross-cultural validity of the remaining etics will be stronger because the exploration of emics has been more exhaustive. All three studies we reviewed bring us closer to cultural completeness by extending theory and increasing the awareness of the existence of certain emics. However, rather than end up at this point through additional studies and the re-examination of certain phenomenon in different cultural contexts, we encourage cross-cultural researchers to aim for this point from the outset. If cultural completeness is an explicit goal from the start, we anticipate that research will be more thoroughly cross-cultural and findings, thus, more robust and generalisable.

\subsection{Contextualise and meaningfully incorporate indigenous thought and knowledge}

Contextualisation of theories, research methods and findings and incorporating indigenous thought and knowledge into developing and testing theories and generating new knowledge has often appeared in a piecemeal fashion in the cross-cultural literature. This motivates the question: Have we moved away from what Boyacigiller and Adler (1991) called 'contextual parochialism'? Are we still slaves to 'thin description', reproduction and insulating from challenges by not seriously accounting for context and by not carefully studying indigenous literature to address the questions and issues we examine?

The authors of the three studies we presented have paid careful attention to their respective research settings and integrated indigenous thought and knowledge into their theorising, methodologies and analyses. They demonstrate beautifully that context drives to a great extent how phenomena are perceived and abstracted at conceptual level and how this results in different constructs and relationships. Relying to a great extent on indigenous thought, these studies have shed light on the limitations of existing theories to explain local phenomena and were able to add new concepts into existing theories and methodologies.

\section{Beyond the three studies: studying carefully intra-cultural variation}

We would like to conclude our paper by looking beyond the three studies and take up an issue that we have not touched upon, but we argue, will be of an increasing importance to cross-cultural researchers in the years to come. Along with other researchers, we advocate the importance of taking seriously into account that cross-cultural variability should not make cross-cultural researchers blind to existing intra-cultural variation, variation that refers to the distribution of an attribute of individuals within a culture (Au, 1999). We would argue that within-culture variation is not only non-negligible, but of high theoretical importance and so, it deserves to be 'conceptualised as a focal construct as opposed to merely a statistical prerequisite for aggregation' [Chan, (1998), p.239].

Many studies have examined culture as divided cleanly along country (national) borders and have emphasised typical members of single cultures, operationalised by cultural means and represented as some central tendencies of single cultures (Au and Cheung, 2004). This has made the country the main or preferred unit of analysis and comparison and has resulted in viewing national cultures as rather homogeneous and 
uniform entities. More than 30 years ago, Pelto and Pelto (1975) referred to this as 'typical cultural patterning' (p.1) and 'uniform cultural rules from which only a few people deviate' (p.3). A consequence of such development in research is the somewhat suppressed importance of characteristics such as ethnicity, religion, generational issues, language, territorial affiliation and regional differences within countries. Intra-cultural cognitive, attitudinal, and behavioural diversity, while essential for understanding cross-cultural variation, have received much less attention in the existing management literature.

To be sure, we are not suggesting that it is unjustifiable to compare countries and/or national cultures in cross-cultural research. History has shaped nations/states, which have developed sets of government policies, laws and regulations concerning several issues, e.g., education, immigration, media, trade, taxation. Our argument is rather that

a nations themselves are becoming increasingly diverse

b such type of unity and homogeneity should not suppress the analysis of existing

intra-cultural variations along various dimensions.

To exemplify, rather than analysing the US as an individualistic culture, in many instances, it would be appropriate to be aware of the substantial regional variation along the individualism-collectivism dimension within the US. Vandello and Cohen (1999) demonstrated that individualism was dominating in some states while other states showed more collectivistic tendencies. Realo et al. (1997) showed that even in a very small country, there could be different patterns of collectivism, which the authors found to be associated with various socio-demographic groups. These and many other studies seriously question the 'fallacious assumption of cultural homogeneity within nations' [Tung, (2008), p.41]. Egri and Ralston (2004) examined generational (sub)cultures in China and concluded that younger generation's values are partly shifting from well-established, conventional views of Chinese culture, also indicating that culture is not stable over time. Furthermore, Fan (2000) argued that while Chinese cultural values apply to people wherever they live, cultural variations exist between mainland China, Hong Kong, Taiwan, and overseas Chinese. In sum, as both Au (1999) and Schwartz and Sagie (2000) showed, there is no consistent relationship between intra-cultural variations and cultural means. While much research exists around the latter, more needs to be done in relation to the former. To this end, we believe that our core suggestions of identifying emics, aiming for cultural completeness, and utilising indigenous knowledge will also assist cross-cultural researchers in mapping intra-cultural variance. We hope the European Journal of Cross-Cultural Competence and Management will provide the opportunity to publish such research that will elevate the overall quality of cross-cultural investigations.

\section{References}

$\mathrm{Au}, \mathrm{K}$. (1999) 'Intra-cultural variation: evidence and implications for international business', Journal of International Business Studies, Vol. 30, pp.799-812.

$\mathrm{Au}, \mathrm{K}$. and Cheung, M.W.L. (2004) 'Intra-cultural variation and job autonomy in 42 countries', Organization Studies, Vol. 25, No. 8, pp.1339-1362.

Boyacilliger, N. and Adler, N.A. (1991) 'The parochial dinosaur: organizational science in a global context', Academy of Management Review, Vol. 16, No. 2, pp.262-290. 
Butcher, J.N. (1985) 'Current development in MMPI use: an inter-national perspective', in J.N. Butcher and C.D. Spielberger (Eds.): Advances in Personality Assessment, Vol. 4, pp.83-94, Lawrence Erlbaum, Hillsdale, NJ.

Chan, D. (1998) 'Functional relations among constructs in the same content domain at different levels of analysis: a typology of composition models', Journal of Applied Psychology, Vol. 83, No. 2, pp.234-246.

Cheung, F.M. (1985) 'Cross-cultural considerations for the translation and adaptation of the Chinese MPI in Hong Kong', in J.N. Butcher and C.D. Spielberger (Eds.): Advances in Personality Assessment, Lawrence Erlbaum, Hillsdale, NJ, Vol. 4, pp.131-158,

Cheung, F.M., Leung, K., Fan, R.M., Song, W.Z., Zhang, J.X. and Zhang, J.P. (1996) 'Development of the Chinese personality assessment inventory', Journal of Cross-Cultural Psychology, Vol. 27, No. 2, pp.181-199.

Cheung, F.M., Leung, K., Zhang, J.X., Sun, H.F., Gan, Y.Q., Song, W.Z. and Xie, D. (2001) 'Indigenous Chinese personality constructs', Journal of Cross-Cultural Psychology, Vol. 32, No. 4, pp.407-433.

Chinese Culture Connection (1987) 'Chinese values and the search for culture-free dimensions of culture', Journal of Cross-Cultural Psychology, Vol. 18, No. 2, pp.143-164.

Easterby-Smith, M. and Malina, D. (1999) 'Cross-cultural collaborative research: toward reflexivity', Academy of Management Journal, Vol. 42, No. 1 pp.76-86.

Egri, C.P. and Ralson, D.A. (2004) 'Generation cohorts and personal values: a comparison of China and the United States', Organization Science, Vol. 15, No. 2, pp.210-220.

Fan, Y. (2000) 'A classification of Chinese culture', Cross-Cultural Management - An International Journal, Vol. 7, No. 2, pp.3-10.

Fang, T. (2003) 'A critique of Hofstede's fifth national culture dimension', International Journal of Cross Cultural Management, Vol. 3, No. 3, pp.347-368.

Farh, J.L., Earley, P.C. and Lin, S.C. (1997) 'Impetus for action: a cultural analysis of justice and organizational citizenship behavior in Chinese society', Administrative Science Quarterly, Vol. 42, No. 3, pp.421-444.

Frese, M. (2005) 'Grand theories and mid-range theories: cultural effects on theorizing and the attempt to understand active approaches to work', in K.G. Smith and M.A. Hitt (Eds.): Great Minds in Management: The Process of Theory Development, Oxford University Press, pp.84-108.

Hofstede, G. (1980) Culture's Consequences: International Differences in Work-related Values, Sage Publications, Newbury Park, CA.

Hofstede, G. (1994) 'Management scientists are human', Management Science, Vol. 40, No. 1, pp.4-13.

Hofstede, G. (2001) Culture's Consequences: Comparing Values, Behaviors, Institutions, and Organizations Across Nations, Sage Publications, Thousand Oaks, CA.

Newman, K.L. and Nollen, S.D. (1996) 'Culture and congruence: the fit between management practices and national culture', Journal of International Business Studies, Vol. 27, No. 4, pp.753-779.

Organ, D.W. (1988) Organizational Citizenship Behavior: The 'Good Solider' Syndrome, Lexington Books, Lexington, MA.

Pelto, P.J. and Pelto, G.H. (1975) 'Intra-cultural diversity: some theoretical issues', American Ethnologist, Vol. 2, pp.1-18.

Podsakoff, P.M., MacKenzie, S.B., Moorman, R.H. and Fetter, R. (1990) 'Transformational leader behaviors and their effects on followers' trust in leader, satisfaction, and organizational citizenship behaviors', Leadership Quarterly, Vol. 1, No. 2, pp.107-142.

Realo, A., Alik, J. and Vadi, M. (1997) 'The hierarchical structure of collectivism', Journal of Research in Personality, Vol. 31, pp.93-116.

Rokeach, M. (1973) The Nature of Human Values, Free Press, New York. 
Schwartz, S. (1992) 'Universal in the content and structure of values: theoretical advances in empirical tests in 20 countries', in M.P. Zanna (Ed.): Advances in Experimental Social Psychology, Vol. 25, pp.1-65.

Schwartz, S.H. and Sagie, G. (2000) 'Value consensus and importance: a cross-national study', Journal of Cross-Cultural Psychology, Vol. 31, pp.465-497.

Triandis, H. and Marin, G. (1983) 'Etic plus emic versus pseudoetic', Journal of Cross-Cultural Psychology, Vol. 14, No. 4, pp.489-500.

Tsui, A.S., Nifadkar, S.S. and Ou, A.Y. (2007) 'Cross-national, cross-cultural organizational behavior research: advances, gaps and recommendations', Journal of Management, Vol. 33, No. 3, pp.426-478.

Tung, R.L. (2008) 'The cross-cultural research imperative: the need to balance cross-national and intra-national diversity', Journal of International Business Studies, Vol. 39, pp.41-46.

Vandello, J.A. and Cohen, D. (1999) 'Patterns of individualism and collectivism across the United States', Journal of Personality and Social Psychology, Vol. 77, pp.279-292. 